\title{
Maple and hickory leaf litter fungal communities reflect pre- senescent leaf communities
}

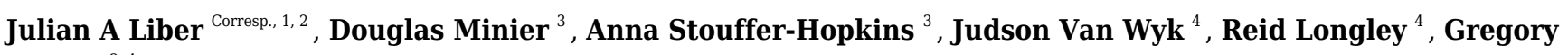 \\ Bonito $^{3,4}$ \\ ${ }^{1}$ Department of Plant Biology, Michigan State University, East Lansing, MI, United States \\ 2 Department of Biology, Duke University, Durham, North Carolina, United States \\ 3 Department of Plant, Soil, and Microbial Sciences, Michigan State University, East Lansing, Michigan, United States \\ 4 Department of Microbiology and Molecular Genetics, Michigan State University, East Lansing, Michigan, United States \\ Corresponding Author: Julian A Liber \\ Email address: julian.liber@duke.edu
}

Fungal communities are known to contribute to the functioning of living plant microbiomes as well as to the decay of dead plant material and affect vital ecosystem services, such as pathogen resistance and nutrient cycling. Yet, factors that drive structure and function of phyllosphere mycobiomes and their fate in leaf litter are often ignored. We sought to determine the factors contributing to the composition of communities in temperate forest substrates, with culture-independent amplicon sequencing of fungal communities of presenescent leaf surfaces, internal tissues, leaf litter, underlying humus soil of co-occurring red maple (Acer rubrum) and shagbark hickory (Carya ovata). Paired samples were taken at five sites within a temperate forest in southern Michigan, USA. Fungal communities were differentiable based on substrate, host species, and site, as well as all two-way and three-way interactions of these variables. PERMANOVA analyses and co-occurrence of taxa indicate that soil communities are unique from both phyllosphere and leaf litter communities. Correspondence of endophyte, epiphyte, and litter communities suggests dispersal plays an important role in structuring fungal communities. Future work will be needed to assess how this dispersal changes microbial community functioning in these niches. 


\section{Maple and hickory leaf litter fungal communities reflect} 2 pre-senescent leaf communities

3

4

5 6

7

8

9 10 11 USA

$12{ }^{4}$ Department of Microbiology and Molecular Genetics, Michigan State University, East Lansing,

13 MI, USA

14

15

16

17

18

19

Julian A. Liber ${ }^{1,2}$, Douglas Minier ${ }^{3}$, Anna Stouffer-Hopkins ${ }^{3}$, Judson Van Wyk ${ }^{4}$, Reid Longley ${ }^{4}$, Gregory Bonito ${ }^{3,4}$

${ }^{1}$ Department of Plant Biology, Michigan State University, East Lansing, MI, USA

${ }^{2}$ Department of Biology, Duke University, Durham, NC, USA

${ }^{3}$ Department of Plant Soil and Microbial Sciences, Michigan State University, East Lansing, MI,

Corresponding Author:

Julian A. Liber ${ }^{1,2}$

Room 137, Biological Sciences Building, 130 Science Drive, Duke University, Durham, NC 27708

Email address: julian.liber@duke.edu 


\section{Abstract}

Fungal communities are known to contribute to the functioning of living plant microbiomes as well as to the decay of dead plant material and affect vital ecosystem services, such as pathogen resistance and nutrient cycling. Yet, factors that drive structure and function of phyllosphere mycobiomes and their fate in leaf litter are often ignored. We sought to determine the factors contributing to the composition of communities in temperate forest substrates, with culture-independent amplicon sequencing of fungal communities of pre-senescent leaf surfaces, internal tissues, leaf litter, underlying humus soil of co-occurring red maple (Acer rubrum) and shagbark hickory (Carya ovata). Paired samples were taken at five sites within a temperate forest in southern Michigan, USA. Fungal communities were differentiable based on substrate, host species, and site, as well as all two-way and three-way interactions of these variables. PERMANOVA analyses and co-occurrence of taxa indicate that soil communities are unique from both phyllosphere and leaf litter communities. Correspondence of endophyte, epiphyte, and litter communities suggests dispersal plays an important role in structuring fungal communities. Future work will be needed to assess how this dispersal changes microbial community functioning in these niches. Introduction

Plant and soil microbiomes contribute to critical ecosystem functions and are involved in complex interactions within communities (Delgado-Baquerizo et al., 2016; Wagg et al., 2019; Regalado et al., 2020). The community of fungi present in the plant microbiome can colonize healthy roots, leaves, stems, and seeds (Porras-Alfaro \& Bayman, 2011; Floc'h et al., 2020). Additionally, fungal communities have been implicated in disease susceptibility (Gu et al., 2020), nutrient acquisition and cycling (Herzog et al., 2019), and stress tolerance or resilience (Waller et al., 2005; Márquez et al., 2007). Yet, fungi also occupy several critical roles in the plant and soil microbial communities, functioning as plant pathogens (Brader et al., 2017), hyperparasites (Falk et al., 1995; Vandermeer, Perfecto \& Liere, 2009), mycorrhizal associates (Soudzilovskaia et al., 2019), saprobes (Zhou \& Hyde, 2001), and specialized litter (Osono, 2007) or wood degraders (Schilling et al., 2020).

Studying the distribution of fungal communities within environments and between living and non-living substrates in a common environment may elucidate the natural history and functional ecology of these organisms (Peay, 2014). Priority effects (Fukami et al., 2010) and environmental filters, such as leaf traits, may be expected to have a role in the assembly of these communities (Purahong et al., 2016). The occurrence of a given taxon across multiple samples suggests dispersal (Bell, 2010). Dispersal processes can lead to priority effects if early arrivals establish and alter the assembly of the community (Hiscox et al., 2015). Furthermore, if environmental filters drive fungal community assembly, samples experiencing similar environments will be expected to be more similar in composition compared to those from environments that differ (Keddy, 1992). The processes of dispersal and filtering are not mutually exclusive, but instead may vary in importance depending on scale, taxa examined, and other factors of the study system (Kivlin et al., 2014; Evans, Martiny \& Allison, 2017).

Fungal endophytes are defined as living asymptomatically within plant tissues (Arnold et al., 2000). The diversity and composition of endophytes can be distinguished from epiphytic communities, the microbes observed on surfaces of plant tissues, but some overlapping taxa are common (Gomes et al., 2018; Yao et al., 2019). In fact, epiphyte communities are presumed to give rise to endophyte communities, as they penetrate openings, such as stomata or damaged tissues (Porras-Alfaro \& Bayman, 2011). Some authors have hypothesized potential ecological 
66 roles of endophytic fungi, including as plant pathogens, latent saprotrophs, or mutualists

67 (Veneault-Fourrey \& Martin, 2011; Brader et al., 2017; Chen et al., 2018). Following senescence

68 of above-ground tissues, some of the endophytes and epiphytes (collectively the phyllosphere

69 community) may switch nutritional modes to become active saprotrophs (Promputtha et al.,

70 2007; He et al., 2012; Gundel et al., 2017) in forest floor leaf litter communities.

Examinations of plant-associated fungal communities have implicated multiple drivers in community composition and diversity. Rhizosphere communities have shown to be structured inpart by plant host species, location, and land-use effects (Bonito et al., 2019; Schöps et al., 2020). Similarly, aboveground tree endophytes showed significant discrimination based on plant tissue, host species, and site in a hemiboreal forest (Küngas, Bahram \& Põldmaa, 2020). Host species identity may account for variation in endophyte community composition even while phylogenetic distance does not (Kembel et al., 2014; Whitaker et al., 2020), which may instead be accounted for by functional traits (Kembel et al., 2014). Variation in leaf secondary metabolites has also been linked with fungal endophyte community composition in some cases (Christian et al., 2020). In a more detailed examination of site effects, environmental characteristics such as rainfall and elevation were demonstrated as important factors in fungal endophyte community composition across the range of a genetically undifferentiated host tree population (Zimmerman and Vitousek, 2012). These site effects may be more pronounced than genetic effects, as was shown in ecotypes of switchgrass (Panicum virgatum) grown in local and remote common gardens (Whitaker et al., 2018).

In the current study, we ask whether endophytic and epiphytic fungal phyllosphere communities of forest tree species differ, and whether phyllosphere fungal taxa may persist in leaf litter or soil communities. To address these questions, fungal communities of pre-senescent leaves, leaf litter and soils were assessed with high-throughput amplicon sequencing and compared. We compared fungal communities of red maple (Acer rubrum L.) and shagbark hickory (Carya ovata (Mill.) K.Koch) host tree species at five sites within a forest ecosystem in southern Michigan where the species co-occur. Based on previous studies of fungal endophytes, we hypothesized that phyllosphere fungal communities between the two plant species would differ. We also expected that many detected endophytic taxa would persist in leaf litter samples, but less so in soils. To determine how these niches structured communities, we sampled across four forest substrates: 1) the surface of pre-senescent leaves, 2) the internal tissues of presenescent leaves, 3) leaf litter, and 4) the soil in direct contact with the leaf litter.

Sampling protocols and downstream sample processing can have overlooked effects on the microbial community analyses (Hallmaier-Wacker et al., 2018). The methods and materials chosen can bias the community observed through DNA extraction and PCR/primer decisions (Brooks et al., 2015). While much research has focused on comparison of kit or DNA extraction methods (Vo \& Jedlicka, 2014; Brooks et al., 2015; Hallmaier-Wacker et al., 2018; Angebault et al., 2020), we did not find literature assessing swab material type for observation of phyllosphere communities. A second aim of this study was to compare the efficacy of swab types composed of two different materials in assessing epiphytic leaf communities with the goal of promoting costefficient yet consistent and thorough environmental sampling. 
107

108

109

110

111

112

113

114

115

116

117

118

119

120

121

122

123

124

125

126

127

128

129

130

131

132

133

134

135

136

137

138

139

140

141

142

143

144

145

146

147

148

149

150

151

152

\section{Materials \& Methods}

Site

Samples were collected within a 9-hectare quadrat in a semi-homogeneous deciduous forest site within Dansville State Game Area, Dansville, Michigan, USA (N 42.5171, W 84.3260, altitude $291 \mathrm{~m}$ ) and approved by the Michigan Department of Natural Resources. Soil types in the quadrat included loam, sandy loam, and loamy sand, and fall under the following USDA soil taxonomy classifications: Oxyaquic Glossudalfs, Typic Endoaquolls, Aquollic Hapludalfs, Aquic Arenic Hapludalfs (Figure S1). Mean annual climate observed at Jackson County Airport, $30.7 \mathrm{~km} \mathrm{SSW}$ of the site, was $800 \mathrm{~mm}$ precipitation, $9.1^{\circ} \mathrm{C}$ temperature, and $69 \%$ relative humidity. Altitude measurements were performed using Google Earth Pro (ver. 7.3.2). Distances between sites were determined using the "Measure distance" function in Google Maps.

\section{Sample collection}

Samples were collected on September 16, 2018 from five sites 76-246m apart (Table S1) selected within the study area described above. These include one site each in the northeast, northwest, southeast, southwest, and center areas on the quadrat. At each site at least one shagbark hickory tree (Carya ovata), one red maple tree (Acer rubrum) and at least ten leaves or leaflets of each host's leaf litter beneath the canopy of sampled trees were present. We selected these tree species as they were consistently found across the forest, providing the opportunity to test site effects. The litter collected was intact leaves of the target host, that were presumed to have fallen the previous year. Ten fresh leaves $($ Acer $)$ or leaflets (Carya) per tree per site were collected axenically from branches within reaching or jumping height ( $<3 \mathrm{~m}$ from ground) and swabbed in the field as a single pooled sample per site, host tree species, and swab type, then transported to the laboratory for further processing. The entire surface of the leaf or leaflet, both top and bottom, was swabbed for those used. For each site and tree, three leaves or leaflets of litter were collected (separately for each host species), and the topsoil (mull humus, about $10 \mathrm{~g}$ ) immediately below the leaves was collected with a sterilized metal scoop. One pooled sample was produced for each combination of site, host tree species, and substrate for the leaf endophyte, litter, and soil samples. Because only a single tree for each species at each site was sampled, we were not able to differentiate whether inter-individual variation was due to withinspecies genotype variability or site environment variability. All collected leaf and soil materials were stored in sterile sealed plastic bags, placed in an insulated cooler, brought directly back to the lab, and stored at $4^{\circ} \mathrm{C}$ until processing (over the following week). All samples of a given substrate were processed on the same day.

Ten leaves or leaflets of each tree at each site were swabbed with two swabs that were dipped in Extraction Solution (ES - $100 \mathrm{mM}$ Tris, $250 \mathrm{mM} \mathrm{KCl}, 10 \mathrm{mM}$ disodium EDTA, adjusted to $\mathrm{pH}$ 9.5-10) directly prior to sampling, producing two extractions per tree and site. Leaves were swabbed with both cotton-tipped applicators and polymer-tipped PurFlock ULTRA $^{\circledR}$ applicators (Puritan Medical Products, Guilford, Maine, USA) referred to as "cotton" and "synthetic", respectively. Swab heads were broken off into individual $2 \mathrm{~mL}$ microcentrifuge tubes and frozen at $-20^{\circ} \mathrm{C}$ until processing. A sterile head of each swab type was placed into ES, exposed to air briefly $(30 \mathrm{sec})$, and placed into the ES to serve as negative controls.

\section{Sample preparation and DNA extraction}

Prior to extraction, $500 \mu \mathrm{L}$ ES was added to each tube containing a swab head. Tubes were heated to $95^{\circ} \mathrm{C}$ for 10 minutes to lyse cells. $500 \mu \mathrm{L}$ of $3 \%$ bovine serum albumin (BSA) was then added to the tubes to stabilize the reaction. This product was mixed, spun down, and the 
153 supernatant was used as template for subsequent PCR reactions (Bonito et al., 2017). To clean 154 and surface sanitize leaves, collected leaf materials were first placed in a solution composed of $15510 \%$ bleach $(0.6 \%$ active sodium hypochlorite $)$ and $0.1 \%$ Tween 20 and agitated for 7 minutes,

156 followed by rinsing in sterile water and drying with sterile filter paper. Surface-sanitized leaves

157 were placed in wax paper bags and lyophilized. Leaf litter was also lyophilized. Leaf litter was

158 not treated to the same epiphyte/endophyte sampling given its non-living and fragile state.

159 Leaves and leaf litter were respectively pooled by host species and site. These composite

160 samples were ground with $6 \mathrm{~mm}$ ceramic beads in $50 \mathrm{~mL}$ centrifuge tubes for $5-10$ minutes

161 using a modified paint shaker (DC-1-C, Miracle Paint Rejuvenator Co, Grove Heights, MN;

162 modified by the Michigan State University Physics Shop).

163 DNA was extracted from lyophilized plant tissue using the Mag-Bind ${ }^{\circledR}$ Plant DNA Kit

164 (Omega Bio-tek, Norcross, GA, USA), with the recommended $\sim 15 \mathrm{mg}$ of dry tissue. Soil

165 samples were dried with silica gel beads and homogenized, then DNA was extracted from $\sim 0.5 \mathrm{~g}$

166 of processed soils with the PowerMag ${ }^{\circledR}$ Soil DNA Isolation Kit (Qiagen, Carlsbad, CA, USA)

167 following manufacturer's recommendations.

168 Fungal amplicon libraries were generated with ITS1f-ITS4 primers (White et al., 1990;

169 Gardes \& Bruns, 1993) and DreamTaq Green DNA Polymerase (ThermoFisher Scientific, USA)

170 following previously described protocols (Lundberg et al., 2013; Chen et al., 2018). Six PCR no-

171 template negative controls were included in library preparation and sequencing. PCR products

172 were visualized under UV light on an ethidium bromide-stained $0.9 \%$ agarose gel after

173 separation by electrophoresis. DNA concentrations of samples were normalized with a

174 SequalPrep ${ }^{\mathrm{TM}}$ Normalization Plate Kit (ThermoFisher Scientific, USA) and samples were then

175 pooled into a single library. Amplicons were then concentrated 20:1 with Amicon ${ }^{\circledR}$ Ultra $0.5 \mathrm{~mL}$

176 50K filters (EMDmillipore, Germany) and purified with Agencourt AMPure XP magnetic beads

177 (Beckman Coulter, USA). A synthetic mock community with 12 taxa and 4 negative (no DNA

178 added) controls were included to assess sequencing quality (Palmer et al., 2018). Amplicons

179 were sequenced on an Illumina MiSeq analyzer using the v3 600 cycles kit (Illumina, USA).

180 Sequence analysis

181 Read quality was assessed with FastQC (Andrews, 2010). Due to the low quality of

182

183

184

185

186

187

188

189

190

191

192

193

194

195

196

197

198 generated reverse reads, only forward reads were carried through for further analysis. Sequences were then demultiplexed in QIIME (Caporaso et al., 2010). Primers were trimmed with Cutadapt 1.18 (Martin, 2011), and the conserved regions trimmed with usearch -fastq filter (Edgar, 2010). Filtered and trimmed reads were then clustered into operational taxonomic units (OTUs) based on $97 \%$ sequence similarity with the uparse pipeline (Edgar, 2013). Fungal OTU classification was determined with the CONSTAX2 consensus technique comparing RDP Classifier, BLAST, and SINTAX algorithms trained on the UNITE fungal general release dataset from Feb 04, 2020 (Abarenkov et al., 2020) with 80\% confidence threshold and recommended settings (Liber, Bonito \& Benucci, 2021). Statistical analyses and plots were prepared in R version 3.6.1 (R Core Team, 2019) using the following packages for plotting and data handling: ggplot2 3.2.1 (Wickham, 2016), patchwork 1.0.0 (Pedersen, 2019), tidyr 1.0.2 (Wickham \& Henry, 2020), dplyr 0.8.3 (Wickham et al., 2019), purrr 0.3.2 (Henry \& Wickham, 2019), ggpubr 0.2.3 (Kassambara, 2019), gplots 3.0.3 (Warnes et al., 2020).

Further identification of indicator OTUs that were poorly classified was completed based upon BLASTn searches (Altschul et al., 1990) against the Fungal RefSeq ITS nucleotide database with default search settings. Taxa were classified based the following prioritized rules: 1) If 1 taxa was greater than $99.5 \%$ identity and $100 \%$ query cover, the species rank was 
199 assigned, 2) if multiple taxa were greater than 95\% identity and $100 \%$ query cover, the lowest

200 rank in common was assigned, 3) if at least five taxa had greater than $80 \%$ identity and $100 \%$

201 query cover, the lowest rank in common was assigned, 4) if fewer than five taxa with $80 \%$

202 identity and $100 \%$ query cover, no taxa was assigned.

203 Ecological analysis

204

205

A rarefaction curve (rarecurve function in vegan 2.5-6) (Oksanen et al., 2019) and OTU table were generated by rarefying to a minimum acceptable depth (function rrarefy from vegan).

206

207

208 Within-sample (alpha) diversity was estimated with phyloseq 1.26.0 (McMurdie \& Holmes, 2013) with both Shannon (Shannon, 1948) and Simpson (Simpson, 1949) diversity indices. Both indices are shown to be minimally biased, but the Shannon index weights rare species more

209

210

211

212

213

214

215

216

217

218

219

220

221

222

223

224

225

226

227

228

229

230

231

232

233 heavily compared to the Simpson index (Mouillot \& Leprêtre, 1999). Effects of substrate, host species, and site on within-sample diversity were examined with linear models, following statistical (Royston, 1995; Shapiro-Wilk test, shapiro.test function) and graphical checks for normality and transformation to obtain normality. Model fits were assessed for homoscedasticity with Breush-Pagan tests using the function bptest in lmtest 0.9-38 (Zeileis \& Hothorn, 2002). Site was used as a variable to account for variation due to host genotype, edaphic effects, and microenvironment not captured by substrate or host species effects. The fit of these models was compared with AICctab from bbmle 1.0.23.1(Anderson \& Burnham, 2002; Bolker \& R Development Core Team, 2020). Fungal community differences within and between substrates were visualized based on Bray-Curtis dissimilarities (Bray \& Curtis, 1957). A Venn diagram and a table of shared OTUs were constructed in VennDiagram 1.6.20 (Chen, 2018) with OTUs having at least $0.01 \%$ weighted abundance. Indicator taxa analysis was performed with rarefied OTU counts with the multipatt function in indicspecies 1.7.6 (De Cáceres \& Legendre, 2009).

Ordinations were performed first with PCoA (function cmdscale in vegan) with BrayCurtis dissimilarity, Sørensen-Dice similarity (Dice, 1945; Sørensen, 1948), and Jaccard similarity (Jaccard, 1901). Based on variance explained, Bray-Curtis dissimilarity was used for subsequent ordination and statistical tests. We applied non-metric multidimensional scaling (NMDS) ordination (metaMDS in vegan) for graphical display of clustering, as clustering was more interpretable than PCoA and yet remained in agreement with later statistical tests. Substrate community compositions were compared by PERMANOVA, for centroids (adonis2 function in vegan for full model, pairwise.perm.manova in RVAideMemoire 0.9-75 for pairwise comparisons) (Hervé, 2020), and by PERMDISP, for dispersion (betadisper function in vegan). Swab material comparisons

To compare the communities sampled by each swab material, PERMANOVA and PERMDISP were performed as described above for substrate, host species, and site comparisons. Swab materials were further compared by within-sample diversity and the number of reads sequenced per sample. The number of reads sequenced were modeled with a negative binomial mixed model with "glmer.nb" from package lme4 1.1-21 (Bates et al., 2015), with swab material as a fixed effect and leaf sampled as a random intercept effect. Within-sample diversity was assessed using a linear mixed model with the same fixed and random effects, with transformations of diversity values to obtain normality. As before, normality was assessed graphically and with Shapiro-Wilk tests, then model fits were assessed for homoscedasticity with Levene's tests (Fox \& Weisberg, 2019).

242 Results

243 Samples and sequencing

244 In this study, a total of 50 samples were collected for fungal community analysis. These 
245

246

247

248

249

250

251

252

253

254

255

256

257

258

259

260

261

262

263

264

265

266

267

268

269

270

271

272

273

274

275

276

277

278

279

280

281

282

283

284

285

286

287

288

289

290

were derived from each of four substrates: leaf surface (20), leaf tissue (10), leaf litter (10), or soil (10), referred to hereafter as "epiphyte", "endophyte", "litter", and "soil". From these samples, amplicon sequencing generated 8,184,524 forward reads, which were reduced to $5,859,924$ after quality filtering and trimming.

Clustering OTUs at $97 \%$ sequence similarity resulted in 3402 OTUs. Any OTUs for which more than half of reads occurred in negative controls were labelled as possible crosscontamination and excluded from further analysis, leaving 3366 OTUs in our sample matrix. A rarefaction curve was performed (Figure S2), which informed the rarefaction to 5926 reads per sample. After sample selection and rarefaction, 18 epiphyte, 10 endophyte, 8 leaf litter, and 10 soil samples remained.

Comparison of substrates, host species, and site

Rarefied OTU counts were ordinated through non-metric multidimensional scaling (NMDS) based upon Bray-Curtis dissimilarity. The first two axes of ordination with PCoA based on Bray-Curtis dissimilarity explained the most variance (34.6\%), compared to abundance-based Sørensen-Dice (32.6\%) or incidence-based Jaccard (25.7\%) indices. Dispersion was significant between all substrates (PERMDISP, $p<0.0001$ ) and pairwise (Tukey's HSD test, $p<0.05$ ) between all pairs of substrates except Epiphyte-Endophyte $(p=0.99)$, and Soil-Litter $(p=1.00)$. Centroids, compared with Bray-Curtis dissimilarity between rarefied OTU counts, were significantly different between all substrates $(p<0.001)$ and pairwise $(p<0.005)$ comparisons based upon PERMANOVA. When host species and substrate combinations were compared with pairwise PERMANOVA, soil was the only substrate that showed no host effect ( $p=0.95$, all others $p<0.05$, Table S2). Substrate was the largest contributing variable to community composition $\left(\mathrm{R}^{2}=0.308, p<0.001\right)$, while host species $\left(\mathrm{R}^{2}=0.075, p<0.001\right)$ and site $\left(\mathrm{R}^{2}=\right.$ $0.086, p<0.001)$ were also significant but contributed less (Table 1). All interactions were significant $(p<0.001)$ with substrate $\mathrm{x}$ site $\left(\mathrm{R}^{2}=0.206\right)$, substrate $\mathrm{x}$ host species $\mathrm{x}$ site $\left(\mathrm{R}^{2}=\right.$ $0.122)$, and substrate $x$ host species $\left(R^{2}=0.106\right)$ accounting for a substantial part of the variability. Within-sample (alpha) diversity values were transformed and tested for normality (Shapiro-Wilk, $p>0.10$ ), and homoscedasticity (Breusch-Pagan, $p>0.10$ ). Mean within-sample diversity was significantly different by substrate (ANOVA, $\mathrm{df}=3, p<0.01$ ) and by host species $(\mathrm{df}=1, p<0.05)$ for both Shannon and Inverse Simpson indices, but notably not by site $(\mathrm{df}=4$, $p>0.10$ ) (Figure S3, Table S3).

Indicator taxa were determined for each of the substrates and substrate groupings, which shows that several leaf-associated taxa were unique to pre-senescent leaves and litter (Table 2). Several indicator taxa are significantly associated with phyllosphere and litter communities, occurring at high abundance across endophyte, epiphyte, and litter (Figure 1). Several taxa are also significantly associated with substrate-host combinations (Table S4). A Pearson correlation heatmap illustrates similarity between phyllosphere and some litter communities at the OTUlevel (Figure S4).

A total of 657 OTUs were identified as having individual weighted abundances greater than $0.01 \%$. The soil environment had the highest number of unique OTUs (212) and the lowest number of shared OTUs (152). The litter had the highest total number of OTUs (421) and the highest number of shared OTUs (357), although not the highest proportion of shared OTUs (Figure 2, Table 3). Community composition based upon the 30 most abundant genera across all samples is consistent with expectations of substrate and host species affinity (Figure 3A). Archaeorhizomycetes, Tuber, Inocybe and other root-associated or ectomycorrhizal fungi (Tedersoo, May \& Smith, 2010; Menkis et al., 2014) were limited to soil samples, while 
291 Ramularia and Ampelomyces, a leaf pathogen and leaf-occuring hyperparasite, respectively (Falk

292

293

294

295

296

297

298

299

300

301

302

303

304

305

306

307

308

309

310

311

312

313

314

315

316

317

318

319

320

321

322

323

324

325

326

327

328

329

330

331

332

333

334

335

336 et al., 1995; Videira et al., 2016) were common in the phyllosphere.

Within each substrate, effects of host species were notable. Endophyte communities of hickory were enriched for Sphaerulina spp. (5.13\% vs $0.030 \%$ in maple) while depleted for Phyllosticta spp. (0.011\% vs 5.30\%) and Seimatosporium spp. (0.045\% vs $1.88 \%)$. Epiphyte communities of hickory were uniquely characterized by Erysiphe $(11.4 \%$ vs $0.019 \%)$ and Golubevia spp. (4.64\% vs 0.70\%), with a much lower abundance of Ampelomyces spp. (4.54\% vs $38.9 \%$ ). OTUs within these genera were significant indicator taxa for their substrate and host species. In leaf litter, some genera were much more abundant in maple litter, including Lareunionomyces ( $4.31 \%$ vs. $0.010 \%$ ), Dothiora ( $0.84 \%$ vs $0.10 \%)$, Ampelomyces $(0.14 \%$ vs $0.030 \%)$, and Saitozyma $(0.047 \%$ vs $0.0034 \%)$, or in hickory such as Periconia $(2.14 \%$ vs $0.051 \%)$, Plectosphaerella (3.73\% vs $0.10 \%)$, and Mycosphaerella $(0.40 \%$ vs $0.030 \%)$. Ramularia (3.99\% in maple vs $10.97 \%$ in hickory), Taphrina $(0.061 \%$ vs $0.14 \%)$ and Scleroramularia $(0.020 \%$ vs $0.0034 \%)$ were between 2- and 6-fold different between host species.

Despite differences in communities based on host species, some core taxa were observed at similar abundance between host species within a substrate. Endophyte communities had taxa such as Ramularia spp. (13.3\% in A. rubrum vs $16.6 \%$ in C. ovata), while in epiphyte communities Ramularia spp. (21.5\% vs 26.2\%), Exobasidium spp. (2.47\% vs $4.11 \%)$, Taphrina spp. (1.51\% vs $2.11 \%)$, and Scleroramularia spp. (1.30\% vs $0.93 \%)$ had similar relative abundances between hosts. Similarly abundant genera in leaf litter were Exobasidium $(0.73 \%$ in Acer rubrum vs $0.50 \%$ in Carya ovata), Seimatosporium (0.091\% vs $0.084 \%)$, Inocybe $(0.017 \%$ in both), Mortierella (sensu lato; $0.010 \%$ in both), and Russula (0.0033\% in both). Ordination with non-metric multidimensional scaling (NMDS) and Bray-Curtis dissimilarity show a broad pattern of fungal communities segregating by substrate, host species, and site (Figure 3B).

Comparison of swab materials

In this study we compared cotton-tipped and synthetic polymer-tipped swabs for collecting epiphytic samples. Total read counts were modeled using a negative binomial mixed model, with a fixed effect of swab material and a random intercept effect of leaf sampled. Read counts per sample were not significantly different between paired cotton and synthetic swab samples (Figure $\mathrm{S} 5)\left(\mathrm{df}=1, p=0.736, \mathrm{z}=-0.338, \mathrm{n}_{\text {samples }}=19, \mathrm{n}_{\text {blocks }}=10\right.$, incidence rate ratio for synthetic : cotton $=0.886,95 \%$ CI $0.432-1.799)$. PERMANOVA was used to compare similarity using rarefied OTU counts and Bray-Curtis distance, and showed no significant difference $(p=0.7)$ between swab types. Dispersion was also not significantly different ( $p=$ 0.36). NMDS ordination of swab (epiphyte) samples demonstrated this overlap of centroids and dispersion between material types (Figure 3C). Comparison of within-sample diversity showed no significant difference between mean diversity for cotton and synthetic samples (Figure 4), with Shannon diversity $(p=0.63, \mathrm{~F}=0.24,95 \% \mathrm{CI}$ difference $=-1.75-2.12)$ or Inverse Simpson $(p=0.69, \mathrm{~F}=0.16, \mathrm{CI}$ difference $=-0.78-1.72)$. However, samples collected with the synthetic swab material had somewhat higher diversity for each metric examined.

\section{Discussion}

In this study, we set out to determine how host species, substrate, and site structured fungal communities in a temperate forest ecosystem. We investigated this question with highthroughput ITS amplicon sequencing of fungal communities from pre-senescent leaves, litter, and soils sampled across five sites and between two host species, shagbark hickory (Carya ovata) and red maple (Acer rubrum). The fungal communities we observed show an effect of 
337 each factor characterized. We observed similar dispersion between endophytes and epiphytes, as

338

339

340

341

342

343

344

345

346

347

348

349

350

351

352

353

354

355

356

357

358

359

360

361

362

363

364

365

366

367

368

369

370

371

372

373

374

375

376

377

378

379

380

381

well as soil and litter, while the litter communities were more similar in composition to presenescent leaf communities than to soil communities. Within-sample diversity varied by substrate and host species, but not site. As reported previously, soil fungal communities were more diverse than litter and phyllosphere communities (Kong et al., 2020). Our results indicate discrete mechanisms of fungal community assembly and maintenance that differ between substrates, and lead to unique spatially explicit fungal communities based on substrate type. Host species, substrate and site contributed most to community structure in our study. These factors have also been deemed significant in other studies (Abdelfattah et al., 2019; Christian et al., 2020; Küngas, Bahram \& Põldmaa, 2020).

Comparing the phyllospheres of maple and hickory

Phyllosphere microbial communities of A. rubrum have previously been examined, but only with culture-based fungal surveys (U'Ren et al., 2012) and amplicon-based bacterial surveys (Laforest-Lapointe, Messier \& Kembel, 2016b). U'Ren et al. (2012) isolated endophytic fungi, which were primarily classified as Pestalotiopsis, Phyllosticta, Colletotrichum, Plagiostoma, and Ramularia spp. These genera accounted for about $29 \%$ of reads in our $A$. rubrum endophyte samples. Seimatosporium spp. composed an additional $1.88 \%$ of these samples. Ampelomyces spp. contributed substantially (38.9\%) to A. rubrum epiphyte communities. While we find consistency across these studies, our culture-independent method allowed for greater sampling depth and likely sequenced taxa that are difficult to culture.

Laforest-Lapointe et al. (2016b) showed an effect of intra- and inter-individual variability on leaf endophyte communities, which may underlie the variation between sampled hosts we observed.

We are unaware of any phyllosphere leaf fungal community studies in C. ovata. Despite growing in the same habitat, our analyses show significant differences in phyllosphere (epiphytic and endophytic) fungal communities between host species, supporting our hypothesis. Carya ovata phyllosphere communities were enriched in Sphaerulina, Erysiphe, and Golubevia spp. compared to A. rubrum.

Fungal communities in maple and hickory leaf litter

As leaves senesce and become litter, priority effects and leaf traits are expected to contribute to the communities observed (Bhatnagar, Peay \& Treseder, 2018; Veen et al., 2019). We observed that host species was a significant determinant of phyllosphere communities, and expected that combined priority effects and leaf trait effects would carry forward community differences between the hosts. While most of the taxa detected in leaf litter (421 OTUs, Figure 2) were also present in the phyllosphere (63\%, 266 OTUs) or soil (34\%, 145 OTUs), around $15 \%$ of the fungal community in the litter was unique to that niche (30\% for maple communities, $11 \%$ for hickory), of which $17 \%$ of the litter unique OTUs were shared between species. Despite a small number of shared OTUs between host species, only a single indicator taxon, annotated as Hypocreales sp. (OTU_50), was found to be significantly associated with hickory litter.

Clustering by NMDS and PERMANOVA tests further support differences between host species. Out of the core litter taxa shared between host species, the roles of Inocybe, Mortierellaceae, and Russula as soil-inhabiting saprobic and ectomycorrhizal fungi (Geml et al., 2010; Seress, Dima \& Kovács, 2016; Vandepol et al., 2020) and their low abundance suggests that these taxa may have been detected as the result of soil clinging to sampled litter. However, for other litter core taxa, abundance patterns existing in phyllosphere pre-senescence appear to continue in litter, for example Exobasidium spp., or reflect a loss of host specificity in the case of Seimatosporium spp.

Peer) reviewing PDF | (2021:04:60641:2:0:NEW 15 Nov 2021) 
382

383

384

385

386

387

388

389

390

391

392

393

394

395

396

397

398

399

400

401

402

403

404

405

406

407

408

409

410

411

412

413

414

415

416

417

418

419

420

421

422

423

424

425

426

427

Fungi detected in the leaf litter are not necessarily derived from either soil or phyllosphere sources. Because the litter we sampled was most likely one year old, it may be possible that OTUs are persistent in the litter, or they may turnover or propagate throughout the season or from year to year. Some fungal taxa are known to persist in temperate forest litter for periods greater than 1 year (Purahong et al., 2016). These taxa, such as specialized basidiomycete litter degraders, may be directly colonizing new litter after it settles on the forest floor.

\section{How do soil and litter fungal communities differ under maple and hickory?}

Soils are known to be hyper-diverse environments (Hu et al., 2019). In this study, soil fungal communities had the highest number of unique OTUs (364) and lowest proportion of shared OTUs (42\%) of any sample type. There were 145 OTUs shared between the litter and the soil, 54 of which were also shared with pre-senescent leaves (19/78 for maple, 37/87 for hickory). These OTUs may have originated in pre-senescent leaves then dispersed to the litter, and then to the soil. Alternately, dispersal could have occurred whereby soil particles carrying fungi reached leaves and litter by wind or rain splash, since soil communities may be reservoirs of phyllosphere diversity (Zarraonaindia et al., 2015). However, our study cannot assess the direction of dispersal. Fungal inoculum in rainfall could be another independent source of inoculum in the sampled substrates (Bell-Dereske and Evans, 2021). Only 22\% (91 of 421) of the OTUs found in the soil were exclusively shared between soil and litter, which indicates a limited contribution of the soil fungal community to that of the litter. Overall, community composition of the soil differed significantly from the other niches sampled (Figure 3A). No differences found between swab types on epiphytic fungal diversity indices

A second research question in this study was whether the swab material used to sample epiphytic communities affected the measured diversity. We found no significant differences between synthetic and cotton swabs in any diversity measurement, including richness, similarity, and read counts. The cost per unit of synthetic swabs are approximately 10 times higher than the cost per unit of cotton swabs, which motivated this research question. These data indicate that future studies can use sterile cotton swabs for sampling without any loss in sampling effectiveness, a more cost-effective strategy.

\section{Limitations and future directions}

Sampling in this study was constrained to a single time point and comparisons of only two host plants. More expansive time-series data would allow for measurements of community assembly, stability, and turnover. Vořišková and Baldrian (2013) proposed that some early fungal diversity in leaf litter may carryover from living leaves. It is possible these taxa were missed by the time we collected samples (late summer). Conducting the experiment earlier in the season, along a temporal transect with more time-discrete sampling, or controlling for this effect by using spore traps (Abdelfattah et al., 2019) could address this issue, and provide a clearer view of the successional changes in fungal communities during leaf senescence and decay. Further, variability in plant microbiomes exists across scales, from intra-individual (Osono \& Mori, 2004; Laforest-Lapointe, Messier \& Kembel, 2016b), to vertically within a canopy (Izuno et al., 2016), geographically within a forest (Cordier et al., 2012), between species (LaforestLapointe, Messier \& Kembel, 2016a), and temporally throughout the year (Materatski et al., 2019). Our sample design was based on sampling of a single tree of each species at each site, thus, we cannot dissect the specific causes of inter-individual variation because genotype, environment, and other individual factors are confounded. At the individual/vertical scale, we only sampled leaves within $3 \mathrm{~m}$ of the ground. Since smaller trees have lower branches, our

Peer] reviewing PDF | (2021:04:60641:2:0:NEW 15 Nov 2021) 
428

429

430

431

432

433

434

435

436

437

438

439

440

441

442

443

444

445

446

447

448

449

450

451

452

453

454

455 sampling was biased towards younger trees that were more accessible, and this may have biased the observed phyllosphere communities. Yet, our results provide a significant contribution by identifying drivers of leaf fungal diversity across the leaf-soil continuum.

Our study dissected factors that affect fungal community structure in forest ecosystems. A more extensive sampling approach incorporating metatranscriptomics, amplification-free metagenomics, and/or genome-based accounting of rDNA copy number could reduce the potential biases inherent in our methods, while also providing increased detail of the functional roles of the organisms in the community, distinguishing dormant or commensal organisms from active saprobes, pathogens, hyperparasites, or mutualists. Finally, to relate fungal communities to ecosystem functions and biochemical processes, surveys of community composition should be combined with host plant phenotypes and measurements of nutrients in litter and soil, leading to insights about host fitness and biogeochemical cycling.

\section{Conclusions}

Our sampling of leaf, leaf litter, and soil microbiomes shows that substrate, host species, site, and the interactions of these factors account for a substantial amount of variation in fungal communities. These factors are indicative of specific influences affecting the community, such as substrate chemistry and local environments. We found that fungal phyllosphere communities differ by host species, an effect which largely persists in the litter community following leaf senescence. We also found that pre-senescent leaf communities overlap substantially with litter community composition, and less so with the soil beneath the leaf litter. Fungal assembly and function of litter communities is complex, thus further studies are needed to address spatial and temporal variability and activity of community members, and their effects on ecosystem processes.

\section{Acknowledgements}

We are grateful to Gian M. N. Benucci and Pedro Beschoren da Costa for helpful discussions, analysis recommendations and data processing guidance. We thank the Department of Plant Soil and Microbial Sciences for teaching resources and support. 
456

457

458

459

460

461

462

463

464

465

466

467

468

469

470

471

472

473

474

475

476

477

478

479

480

481

482

483

484

485

486

487

488

489

490

491

492

493

494

495

496

497

498

499

500

501

\section{References}

Abarenkov K, Zirk A, Piirmann T, Pöhönen R, Ivanov F, Nilsson RH, Kõljalg U. 2020. UNITE general FASTA release for Fungi.

Abdelfattah A, Sanzani SM, Wisniewski M, Berg G, Cacciola SO, Schena L. 2019. Revealing Cues for Fungal Interplay in the Plant-Air Interface in Vineyards. Frontiers in Plant Science 10:922. DOI: 10.3389/fpls.2019.00922.

Altschul SF, Gish W, Miller W, Myers EW, Lipman DJ. 1990. Basic local alignment search tool. Journal of Molecular Biology 215:403-410. DOI: 10.1016/S0022-2836(05)80360-2.

Anderson DR, Burnham KP. 2002. Avoiding pitfalls when using information-theoretic methods. The Journal of Wildlife Management:912-918.

Andrews S. 2010. FastQC: a quality control tool for high throughput sequence data.

Angebault C, Payen M, Woerther P-L, Rodriguez C, Botterel F. 2020. Combined bacterial and fungal targeted amplicon sequencing of respiratory samples: Does the DNA extraction method matter? PLOS ONE 15:e0232215. DOI: 10.1371/journal.pone.0232215.

Arnold AE, Maynard Z, Gilbert GS, Coley PD, Kursar TA. 2000. Are tropical fungal endophytes hyperdiverse? Ecology Letters 3:267-274. DOI: 10.1046/j.1461-0248.2000.00159.x.

Bates D, Mächler M, Bolker B, Walker S. 2015. Fitting Linear Mixed-Effects Models Using \{lme4\}. Journal of Statistical Software 67:1-48. DOI: 10.18637/jss.v067.i01.

Bell T. 2010. Experimental tests of the bacterial distance-decay relationship. The ISME Journal 4:1357-1365. DOI: 10.1038/ismej.2010.77.

Bhatnagar JM, Peay KG, Treseder KK. 2018. Litter chemistry influences decomposition through activity of specific microbial functional guilds. Ecological Monographs 88:429-444. DOI: https://doi.org/10.1002/ecm.1303.

Bolker B, R Development Core Team. 2020. bbmle: Tools for General Maximum Likelihood Estimation.

Bonito G, Benucci GMN, Hameed K, Weighill D, Jones P, Chen KH, Jacobson D, Schadt C, Vilgalys R. 2019. Fungal-bacterial networks in the Populus rhizobiome are impacted by soil properties and host genotype. Frontiers in Microbiology 10:1-21. DOI: 10.3389/fmicb.2019.00481.

Bonito G, Hameed K, Toome-Heller M, Healy R, Reid C, Liao H-LL, Aime MC, Schadt C, Vilgalys R. 2017. Atractiella rhizophila, sp. nov., an endorrhizal fungus isolated from the Populus root microbiome. Mycologia 109:18-26. DOI: 10.1080/00275514.2016.1271689.

Brader G, Compant S, Vescio K, Mitter B, Trognitz F, Ma L-J, Sessitsch A. 2017. Ecology and Genomic Insights into Plant-Pathogenic and Plant-Nonpathogenic Endophytes. Annual Review of Phytopathology 55:61-83. DOI: 10.1146/annurev-phyto-080516-035641.

Bray JR, Curtis JT. 1957. An Ordination of the Upland Forest Communities of Southern Wisconsin. Ecological Monographs 27:325-349. DOI: 10.2307/1942268.

Brooks JP, Edwards DJ, Harwich MD, Rivera MC, Fettweis JM, Serrano MG, Reris RA, Sheth NU, Huang B, Girerd P, Strauss JF, Jefferson KK, Buck GA. 2015. The truth about metagenomics: Quantifying and counteracting bias in 16S rRNA studies Ecological and evolutionary microbiology. BMC Microbiology 15:66. DOI: 10.1186/s12866-015-0351-6.

De Cáceres M, Legendre P. 2009. Associations between species and groups of sites: Indices and statistical inference. Ecology 90:3566-3574. DOI: 10.1890/08-1823.1.

Caporaso JG, Kuczynski J, Stombaugh J, Bittinger K, Bushman FD, Costello EK, Fierer N, Pẽa AG, Goodrich JK, Gordon JI, Huttley GA, Kelley ST, Knights D, Koenig JE, Ley RE, Lozupone CA, McDonald D, Muegge BD, Pirrung M, Reeder J, Sevinsky JR, Turnbaugh 
502

503

504

505

506

507

508

509

510

511

512

513

514

515

516

517

518

519

520

521

522

523

524

525

526

527

528

529

530

531

532

533

534

535

536

537

538

539

540

541

542

543

544

545

546

547
PJ, Walters WA, Widmann J, Yatsunenko T, Zaneveld J, Knight R. 2010. QIIME allows analysis of high-throughput community sequencing data. Nature Methods 7:335-336. DOI: 10.1038/nmeth.f.303.

Chen H. 2018. VennDiagram: Generate High-Resolution Venn and Euler Plots.

Chen KH, Liao HL, Arnold AE, Bonito G, Lutzoni F. 2018. RNA-based analyses reveal fungal communities structured by a senescence gradient in the moss Dicranum scoparium and the presence of putative multi-trophic fungi. New Phytologist 218:1597-1611. DOI: 10.1111/nph.15092.

Christian N, Sedio BE, Florez-Buitrago X, Ramírez-Camejo LA, Rojas EI, Mejía LC, Palmedo S, Rose A, Schroeder JW, Herre EA. 2020. Host affinity of endophytic fungi and the potential for reciprocal interactions involving host secondary chemistry. American Journal of Botany 107:219-228. DOI: 10.1002/ajb2.1436.

Cordier T, Robin C, Capdevielle X, Desprez-Loustau ML, Vacher C. 2012. Spatial variability of phyllosphere fungal assemblages: Genetic distance predominates over geographic distance in a European beech stand (Fagus sylvatica). Fungal Ecology 5:509-520. DOI:

10.1016/j.funeco.2011.12.004.

Delgado-Baquerizo M, Giaramida L, Reich PB, Khachane AN, Hamonts K, Edwards C, Lawton LA, Singh BK. 2016. Lack of functional redundancy in the relationship between microbial diversity and ecosystem functioning. Journal of Ecology 104:936-946. DOI: 10.1111/13652745.12585.

Dice LR. 1945. Measures of the Amount of Ecologic Association Between Species. Ecology 26:297-302. DOI: 10.2307/1932409.

Edgar RC. 2010. Search and clustering orders of magnitude faster than BLAST. Bioinformatics 26:2460-2461. DOI: 10.1093/bioinformatics/btq461.

Edgar RC. 2013. UPARSE: highly accurate OTU sequences from microbial amplicon reads. Nature Methods 10:996-998. DOI: 10.1038/nmeth.2604.

Evans S, Martiny JBH, Allison SD. 2017. Effects of dispersal and selection on stochastic assembly in microbial communities. The ISME Journal 11:176-185. DOI: 10.1038/ismej.2016.96.

Falk SP, Gadoury DM, Cortesi P, Pearson RC, Seem RC. 1995. Parasitism of Uncinula necator cleistothecia by the mycoparasite Ampelomyces quisqualis. Phytopathology 85:794-800.

Floc'h J-B, Hamel C, Harker KN, St-Arnaud M. 2020. Fungal Communities of the Canola Rhizosphere: Keystone Species and Substantial Between-Year Variation of the Rhizosphere Microbiome. Microbial Ecology 80:762-777. DOI: 10.1007/s00248-019-01475-8.

Fox J, Weisberg S. 2019. An R Companion to Applied Regression. Thousand Oaks CA: Sage. Fukami T, Dickie IA, Paula Wilkie J, Paulus BC, Park D, Roberts A, Buchanan PK, Allen RB. 2010. Assembly history dictates ecosystem functioning: Evidence from wood decomposer communities. Ecology Letters 13:675-684. DOI: 10.1111/j.1461-0248.2010.01465.x.

Gardes M, Bruns TD. 1993. ITS primers with enhanced specificity for basidiomycetes application to the identification of mycorrhizae and rusts. Molecular Ecology 2:113-118. DOI: 10.1111/j.1365-294X.1993.tb00005.x.

Geml J, Laursen GA, Herriott IC, McFarland JM, Booth MG, Lennon N, Nusbaum HC, Taylor DL. 2010. Phylogenetic and ecological analyses of soil and sporocarp DNA sequences reveal high diversity and strong habitat partitioning in the boreal ectomycorrhizal genus Russula (Russulales; Basidiomycota). New Phytologist:14.

Gomes T, Pereira JA, Benhadi J, Lino-Neto T, Baptista P. 2018. Endophytic and Epiphytic 
548

549

550

551

552

553

554

555

556

557

558

559

560

561

562

563

564

565

566

567

568

569

570

571

572

573

574

575

576

577

578

579

580

581

582

583

584

585

586

587

588

589

590

591

592

593

Phyllosphere Fungal Communities Are Shaped by Different Environmental Factors in a Mediterranean Ecosystem. Microbial Ecology 76:668-679. DOI: 10.1007/s00248-0181161-9.

Gu Z, Wang M, Wang Y, Zhu L, Mur LAJ, Hu J, Guo S. 2020. Nitrate Stabilizes the Rhizospheric Fungal Community to Suppress Fusarium Wilt Disease in Cucumber. Molecular Plant-Microbe Interactions 33:590-599. DOI: 10.1094/MPMI-07-19-0198-R. Gundel PE, Helander M, Garibaldi LA, Vázquez-de-Aldana BR, Zabalgogeazcoa I, Saikkonen K. 2017. Direct and indirect effects of the fungal endophyte Epichloë uncinatum on litter decomposition of the host grass, Schedonorus pratensis. Plant Ecology 218:1107-1115. DOI: $10.1007 / \mathrm{s} 11258-017-0755-5$.

Hallmaier-Wacker LK, Lueert S, Roos C, Knauf S. 2018. The impact of storage buffer, DNA extraction method, and polymerase on microbial analysis. Scientific Reports 8:6292. DOI: 10.1038/s41598-018-24573-y.

He X, Han G, Lin Y, Tian X, Xiang C, Tian Q, Wang F, He Z. 2012. Diversity and decomposition potential of endophytes in leaves of a Cinnamomum camphora plantation in China. Ecological Research 27:273-284. DOI: 10.1007/s11284-011-0898-0.

Henry L, Wickham H. 2019. purrr: Functional Programming Tools.

Hervé M. 2020. RVAideMemoire: Testing and Plotting Procedures for Biostatistics.

Herzog C, Hartmann M, Frey B, Stierli B, Rumpel C, Buchmann N, Brunner I. 2019. Microbial succession on decomposing root litter in a drought-prone Scots pine forest. The ISME Journal 13:2346-2362. DOI: 10.1038/s41396-019-0436-6.

Hiscox J, Savoury M, Müller CT, Lindahl BD, Rogers HJ, Boddy L. 2015. Priority effects during fungal community establishment in beech wood. The ISME Journal 9:2246-2260. DOI: 10.1038/ismej.2015.38.

Hu Y, Veresoglou SD, Tedersoo L, Xu T, Ge T, Liu L, Chen Y, Hao Z, Su Y, Rillig MC, Chen B. 2019. Contrasting latitudinal diversity and co-occurrence patterns of soil fungi and plants in forest ecosystems. Soil Biology and Biochemistry 131:100-110. DOI: 10.1016/j.soilbio.2019.01.001.

Izuno A, Kanzaki M, Artchawakom T, Wachrinrat C, Isagi Y. 2016. Vertical Structure of Phyllosphere Fungal Communities in a Tropical Forest in Thailand Uncovered by HighThroughput Sequencing. PLOS ONE 11:e0166669. DOI: 10.1371/journal.pone.0166669.

Jaccard P. 1901. Étude comparative de la distribution florale dans une portion des Alpes et des Jura. Bull Soc Vaudoise Sci Nat 37:547-579.

Kassambara A. 2019. ggpubr: "ggplot2" Based Publication Ready Plots.

Keddy PA. 1992. Assembly and response rules: two goals for predictive community ecology. Journal of Vegetation Science 3:157-164. DOI: 10.2307/3235676.

Kembel SW, *, Mueller RC, *. 2014. Plant traits and taxonomy drive host associations in tropical phyllosphere fungal communities. Botany 92:303-311. DOI: 10.1139/cjb-20130194.

Kivlin SN, Winston GC, Goulden ML, Treseder KK. 2014. Environmental filtering affects soil fungal community composition more than dispersal limitation at regional scales. Fungal Ecology 12:14-25. DOI: 10.1016/j.funeco.2014.04.004.

Kong X, Han Z, Tai X, Jin D, Ai S, Zheng X, Bai Z. 2020. Maize (Zea mays L. Sp.) varieties significantly influence bacterial and fungal community in bulk soil, rhizosphere soil and phyllosphere. FEMS Microbiology Ecology 96. DOI: 10.1093/femsec/fiaa020.

Küngas K, Bahram M, Põldmaa K. 2020. Host tree organ is the primary driver of endophytic

Peer] reviewing PDF | (2021:04:60641:2:0:NEW 15 Nov 2021) 
594

595

596

597

598

599

600

601

602

603

604

605

606

607

608

609

610

611

612

613

614

615

616

617

618

619

620

621

622

623

624

625

626

627

628

629

630

631

632

633

634

635

636

637

638

639

fungal community structure in a hemiboreal forest. FEMS Microbiology Ecology 96:fiz199. DOI: $10.1093 /$ femsec/fiz199.

Laforest-Lapointe I, Messier C, Kembel SW. 2016a. Tree phyllosphere bacterial communities: Exploring the magnitude of intra- and inter-individual variation among host species. PeerJ 2016:e2367. DOI: 10.7717/PEERJ.2367.

Laforest-Lapointe I, Messier C, Kembel SW. 2016b. Host species identity, site and time drive temperate tree phyllosphere bacterial community structure. Microbiome 4:1-10. DOI: 10.1186/s40168-016-0174-1.

Liber J, Bonito G, Benucci GMN. 2021. CONSTAX2: Improved taxonomic classification of environmental DNA markers. Bioinformatics 37:3941-3943. DOI: 10.1093/bioinformatics/btab347.

Lundberg DS, Yourstone S, Mieczkowski P, Jones CD, Dangl JL. 2013. Practical innovations for high-throughput amplicon sequencing. Nature Methods 10:999-1002. DOI: 10.1038/nmeth.2634.

Márquez LM, Redman RS, Rodriguez RJ, Roossinck MJ. 2007. A Virus in a Fungus in a Plant: Three-Way Symbiosis Required for Thermal Tolerance. Science 315:513-515. DOI: $10.1126 /$ science. 1136237.

Martin M. 2011. Cutadapt removes adapter sequences from high-throughput sequencing reads. EMBnet.journal 17:10-12. DOI: 10.14806/ej.17.1.200.

Materatski P, Varanda C, Carvalho T, Dias AB, Campos MD, Rei F, Félix M do R. 2019. Spatial and temporal variation of fungal endophytic richness and diversity associated to the phyllosphere of olive cultivars. Fungal Biology 123:66-76. DOI: 10.1016/j.funbio.2018.11.004.

McMurdie PJ, Holmes S. 2013. Phyloseq: An R Package for Reproducible Interactive Analysis and Graphics of Microbiome Census Data. PLoS ONE 8. DOI: 10.1371/journal.pone.0061217.

Menkis A, Urbina H, James TY, Rosling A. 2014. Archaeorhizomyces borealis sp. nov. and a sequence-based classification of related soil fungal species. Fungal Biology 118:943-955. DOI: $10.1016 /$ j.funbio.2014.08.005.

Mouillot D, Leprêtre A. 1999. A comparison of species diversity estimators. Researches on Population Ecology 41:203-215. DOI: 10.1007/s101440050024.

Oksanen J, Blanchet FG, Friendly M, Kindt R, Legendre P, McGlinn D, Minchin PR, O'Hara RB, Simpson GL, Solymos P, Stevens MHH, Szoecs E, Wagner H. 2019. vegan: Community Ecology Package.

Osono T. 2007. Ecology of ligninolytic fungi associated with leaf litter decomposition. Ecological Research 22:955-974. DOI: 10.1007/s11284-007-0390-z.

Osono T, Mori A. 2004. Distribution of phyllosphere fungi within the canopy of giant dogwood. Mycoscience 45:161-168. DOI: 10.1007/S10267-003-0167-3.

Palmer JM, Jusino MA, Banik MT, Lindner DL. 2018. Non-biological synthetic spike-in controls and the AMPtk software pipeline improve mycobiome data. PeerJ 2018:e4925. DOI: 10.7717 peerj.4925.

Peay KG. 2014. Back to the future: natural history and the way forward in modern fungal ecology. Fungal Ecology 12:4-9. DOI: 10.1016/j.funeco.2014.06.001.

Pedersen TL. 2019. patchwork: The Composer of Plots. $R$ package version 1.0.0.

Porras-Alfaro A, Bayman P. 2011. Hidden Fungi, Emergent Properties: Endophytes and Microbiomes. Annual Review of Phytopathology 49:291-315. DOI: 10.1146/annurev-phyto- 
640

641

642

643

644

645

646

647

648

649

650

651

652

653

654

655

656

657

658

659

660

661

662

663

664

665

666

667

668

669

670

671

672

673

674

675

676

677

678

679

680

681

682

683

684

685

080508-081831.

Promputtha I, Lumyong S, Dhanasekaran V, McKenzie EHC, Hyde KD, Jeewon R. 2007. A phylogenetic evaluation of whether endophytes become saprotrophs at host senescence. Microbial Ecology 53:579-590. DOI: 10.1007/s00248-006-9117-x.

Purahong W, Wubet T, Lentendu G, Schloter M, Pecyna MJ, Kapturska D, Hofrichter M, Krüger D, Buscot F. 2016. Life in leaf litter: novel insights into community dynamics of bacteria and fungi during litter decomposition. Molecular ecology 25:4059-4074. DOI: $10.1111 / \mathrm{mec} .13739$.

R Core Team. 2019. R: A Language and Environment for Statistical Computing.

Regalado J, Lundberg DS, Deusch O, Kersten S, Karasov T, Poersch K, Shirsekar G, Weigel D. 2020. Combining whole-genome shotgun sequencing and rRNA gene amplicon analyses to improve detection of microbe - microbe interaction networks in plant leaves. The ISME Journal:2116-2130. DOI: 10.1038/s41396-020-0665-8.

Royston P. 1995. Remark AS R94: A Remark on Algorithm AS 181: The W-test for Normality. Journal of the Royal Statistical Society. Series C (Applied Statistics) 44:547-551. DOI: $10.2307 / 2986146$.

Schilling JS, Kaffenberger JT, Held BW, Ortiz R, Blanchette RA. 2020. Using Wood Rot Phenotypes to Illuminate the "Gray" Among Decomposer Fungi. Frontiers in Microbiology 11:1288. DOI: 10.3389/fmicb.2020.01288.

Schöps R, Goldmann K, Korell L, Bruelheide H, Wubet T, Buscot F. 2020. Resident and phytometer plants host comparable rhizosphere fungal communities in managed grassland ecosystems. Scientific Reports 10:1-11. DOI: 10.1038/s41598-020-57760-x.

Seress D, Dima B, Kovács GM. 2016. Characterisation of seven Inocybe ectomycorrhizal morphotypes from a semiarid woody steppe. Mycorrhiza 26:215-225. DOI: 10.1007/s00572-015-0662-3.

Shannon CE. 1948. A Mathematical Theory of Communication. Bell System Technical Journal 27:379-423. DOI: 10.1002/j.1538-7305.1948.tb01338.x.

Simpson EH. 1949. Measurement of diversity. Nature 163:688. DOI: 10.1038/163688a0.

Sørensen TA. 1948. A method of establishing groups of equal amplitude in plant sociology based on similarity of species content and its application to analyses of the vegetation on Danish commons. Biol. Skar. 5:1-34.

Soudzilovskaia NA, van Bodegom PM, Terrer C, Zelfde M van't, McCallum I, Luke McCormack M, Fisher JB, Brundrett MC, de Sá NC, Tedersoo L. 2019. Global mycorrhizal plant distribution linked to terrestrial carbon stocks. Nature Communications 10:1-10. DOI: 10.1038/s41467-019-13019-2.

Tedersoo L, May TW, Smith ME. 2010. Ectomycorrhizal lifestyle in fungi: Global diversity, distribution, and evolution of phylogenetic lineages. Mycorrhiza 20:217-263. DOI: 10.1007/s00572-009-0274-X.

U'Ren JM, Lutzoni F, Miadlikowska J, Laetsch AD, Elizabeth Arnold A, Arnold AE. 2012. Host and geographic structure of endophytic and endolichenic fungi at a continental scale. American Journal of Botany 99:898-914. DOI: 10.3732/ajb.1100459.

Vandepol N, Liber J, Desirò A, Na H, Kennedy M, Barry K, Grigoriev I V., Miller AN, O’Donnell K, Stajich JE, Bonito G. 2020. Resolving the Mortierellaceae phylogeny through synthesis of multi-gene phylogenetics and phylogenomics. Fungal Diversity 104:267-289. DOI: $10.1007 / \mathrm{s} 13225-020-00455-5$.

Vandermeer J, Perfecto I, Liere H. 2009. Evidence for hyperparasitism of coffee rust (Hemileia 
686

687

688

689

690

691

692

693

694

695

696

697

698

699

700

701

702

703

704

705

706

707

708

709

710

711

712

713

714

715

716

717

718

719

720

721

722

723

724

725

726

727

728

729

730

731

vastatrix) by the entomogenous fungus, Lecanicillium lecanii, through a complex ecological web. Plant Pathology 58:636-641. DOI: https://doi.org/10.1111/j.1365-3059.2009.02067.x.

Veen GF (Ciska., Snoek BL, Bakx-Schotman T, Wardle DA, van der Putten WH. 2019. Relationships between fungal community composition in decomposing leaf litter and homefield advantage effects. Functional Ecology 33:1524-1535. DOI: 10.1111/13652435.13351.

Veneault-Fourrey C, Martin F. 2011. Mutualistic interactions on a knife-edge between saprotrophy and pathogenesis. Current Opinion in Plant Biology 14:444-450. DOI: 10.1016/j.pbi.2011.03.022.

Videira SIR, Groenewald JZ, Braun U, Shin HD, Crous PW. 2016. All that glitters is not Ramularia. Studies in Mycology. DOI: 10.1016/j.simyco.2016.06.001.

Vo ATE, Jedlicka JA. 2014. Protocols for metagenomic DNA extraction and Illumina amplicon library preparation for faecal and swab samples. Molecular Ecology Resources 14:11831197. DOI: $10.1111 / 1755-0998.12269$.

Vořišková J, Baldrian P. 2013. Fungal community on decomposing leaf litter undergoes rapid successional changes. ISME Journal 7:477-486. DOI: 10.1038/ismej.2012.116.

Wagg C, Schlaeppi K, Banerjee S, Kuramae EE, van der Heijden MGA. 2019. Fungal-bacterial diversity and microbiome complexity predict ecosystem functioning. Nature Communications 10:4841. DOI: 10.1038/s41467-019-12798-y.

Waller F, Achatz B, Baltruschat H, Fodor J, Becker K, Fischer M, Heier T, Hückelhoven R, Neumann C, Von Wettstein D, Franken P, Kogel KH. 2005. The endophytic fungus Piriformospora indica reprograms barley to salt-stress tolerance, disease resistance, and higher yield. Proceedings of the National Academy of Sciences of the United States of America 102:13386-13391. DOI: 10.1073/pnas.0504423102.

Warnes GR, Bolker B, Bonebakker L, Gentleman R, Huber W, Liaw A, Lumley T, Maechler M, Magnusson A, Moeller S, Schwartz M, Venables B. 2020. gplots: Various R Programming Tools for Plotting Data.

White TJ, Bruns T, Lee S, Taylor J. 1990. Amplification and Direct Sequencing of Fungal Ribosomal RNA Genes for Phylogenetics. PCR Protocols 18:315-322. DOI: 10.1016/b9780-12-372180-8.50042-1.

Wickham H. 2016. ggplot2: Elegant Graphics for Data Analysis. Springer-Verlag New York.

Wickham H, François R, Henry L, Müller K. 2019. dplyr: A Grammar of Data Manipulation.

Wickham H, Henry L. 2020. tidyr: Tidy Messy Data.

Whitaker BK, Christian N, Chai Q, Clay K. 2020. Foliar fungal endophyte community structure is independent of phylogenetic relatedness in an Asteraceae common garden. Ecology and Evolution 10:13895-13912. DOI: 10.1002/ece3.6983.

Whitaker BK, Reynolds HL, Clay K. 2018. Foliar fungal endophyte communities are structured by environment but not host ecotype in Panicum virgatum (switchgrass). Ecology 99:27032711. DOI: $10.1002 /$ ecy.2543.

Yao H, Sun X, He C, Maitra P, Li X-C, Guo L-D. 2019. Phyllosphere epiphytic and endophytic fungal community and network structures differ in a tropical mangrove ecosystem. Microbiome 7:57. DOI: 10.1186/s40168-019-0671-0.

Zarraonaindia I, Owens SM, Weisenhorn P, West K, Hampton-Marcell J, Lax S, Bokulich NA, Mills DA, Martin G, Taghavi S, others. 2015. The soil microbiome influences grapevineassociated microbiota. MBio 6:e2527--14. DOI: 10.1128/mBio.02527-14.Editor.

Zeileis A, Hothorn T. 2002. Diagnostic Checking in Regression Relationships. R News 2:7-10.

Peer] reviewing PDF | (2021:04:60641:2:0:NEW 15 Nov 2021) 
732 Zhou D, Hyde KD. 2001. Host-specificity, host-exclusivity, and host-recurrence in saprobic 733 fungi. Mycological Research 105:1449-1457. DOI: 10.1017/S0953756201004713.

734 Zimmerman NB, Vitousek PM. 2012. Fungal endophyte communities reflect environmental 735 structuring across a Hawaiian landscape. Proceedings of the National Academy of Sciences 736 109:13022-13027. DOI: 10.1073/pnas.1209872109.

737 


\section{Table $\mathbf{1}$ (on next page)}

PERMANOVA tables of substrate, host species, site, and interactions effects on fungal communities both all factor and pairwise.

Included are both the full model comparison and p-values from permuted pairwise tests. 
1 Table 1. PERMANOVA tables of substrate, host species, site, and interactions effects on

2 fungal communities both all factor and pairwise. Included are both the full model comparison

3 and $p$-values from permuted pairwise tests.

\begin{tabular}{|c|c|c|c|}
\hline \multicolumn{4}{|c|}{ All-factor PERMANOVA test statistics } \\
\hline Factor & $\mathrm{R}^{2}$ & $\mathrm{~F}$ & $\operatorname{Pr}(>F)$ \\
\hline Substrate & 0.3079 & 19.62 & 0.001 \\
\hline Host species & 0.0751 & 14.37 & 0.001 \\
\hline Site & 0.0864 & 4.13 & 0.001 \\
\hline Substrate:Host species & 0.1057 & 6.74 & 0.001 \\
\hline Substrate:Site & 0.2063 & 3.29 & 0.001 \\
\hline Host species:Site & 0.0551 & 2.63 & 0.002 \\
\hline Substrate:Host species:Site & 0.1216 & 2.32 & 0.001 \\
\hline Residual & 0.0418 & & \\
\hline Total & 1 & & \\
\hline \multicolumn{4}{|c|}{ Pairwise PERMANOVA comparisons by substrate } \\
\hline Epiphytes & \multicolumn{2}{|c|}{ Litter } & Soil \\
\hline Endophytes & \multicolumn{2}{|c|}{0.004} & 0.0015 \\
\hline Epiphytes & \multicolumn{2}{|c|}{0.0015} & 0.0015 \\
\hline Litter & \multicolumn{2}{|c|}{-} & 0.0015 \\
\hline
\end{tabular}




\section{Table 2 (on next page)}

Substrate and cross-substrate indicator OTUs.

Indicator OTUs were determined using the multipatt function the indicspecies package. Substrate groupings with no significant indicator OTUs are not displayed, and only those with a false discovery rate (FDR) $<0.05$ are included (maximum of 5 each). Classification against the UNITE with and Fungal RefSeq ITS databases with CONSTAX2 and BLASTn determined the closest known taxa. 
1 Table 2. Substrate and cross-substrate indicator OTUs. Indicator OTUs were determined 2 using the multipatt function the indicspecies package. Substrate groupings with no significant 3 indicator OTUs are not displayed, and only those with a false discovery rate (FDR) $<0.05$ are 4 included (maximum of 5 each). Classification against the UNITE with and Fungal RefSeq ITS 5 databases with CONSTAX2 and BLASTn determined the closest known taxa.

\begin{tabular}{|c|c|c|c|c|}
\hline Substrate & OTU & FDR & CONSTAX2 Result & BLAST Result \\
\hline \multirow[t]{5}{*}{ Epiphyte } & OTU_150 & 0.003 & Fungi sp. & Ceramothyrium sp. \\
\hline & OTU_56 & 0.003 & Golubevia pallescens & Unknown \\
\hline & OTU_58 & 0.003 & Fungi sp. & Unknown \\
\hline & OTU_108 & 0.003 & Mycosphaerellaceae sp. & Acrodontium sp. \\
\hline & OTU_191 & 0.003 & Taphrina vestergrenii & Unknown \\
\hline \multirow[t]{5}{*}{ Endophyte } & OTU_48 & 0.01 & Phyllosticta minima & Phyllosticta sp. \\
\hline & OTU_83 & 0.012 & Seimatosporium sp. & Seimatosporium sp. \\
\hline & OTU_34 & 0.022 & Rhytisma sp. & Rhytismataceae sp. \\
\hline & OTU_683 & 0.033 & Zygophiala tardicrescens & Schizothyrium sp. \\
\hline & OTU_1104 & 0.034 & Hypoxylon carneum & Unknown \\
\hline \multirow[t]{5}{*}{ Litter } & OTU_23 & 0.003 & Colletotrichum sp. & Colletotrichum sp. \\
\hline & OTU_32 & 0.003 & Xylariales sp. & Xylariales sp. \\
\hline & OTU_40 & 0.003 & Codinaea lambertiae & Codinaea lambertiae \\
\hline & OTU_52 & 0.003 & Ascomycota sp. & Coleophoma sp. \\
\hline & OTU_112 & 0.003 & Lophiostoma sp. & Amorocoelophoma sp. \\
\hline \multirow[t]{5}{*}{ Soil } & OTU_19 & 0.003 & Saitozyma podzolica & Saitozyma sp. \\
\hline & OTU_41 & 0.003 & Archaeorhizomyces sp. & Archaeorhizomyces sp. \\
\hline & OTU_85 & 0.003 & Solicoccozyma terricola & Solicocozyma terricola \\
\hline & OTU_93 & 0.003 & Trichoderma hamatum & Trichoderma sp. \\
\hline & OTU 785 & 0.003 & Pseudogymnoascus roseus & Pseudogymnoascus sp. \\
\hline \multirow{5}{*}{$\begin{array}{l}\text { Epiphyte + } \\
\text { Endophyte }\end{array}$} & OTU_189 & 0.003 & Ramularia nyssicola & Ramularia nyssicola \\
\hline & OTU_479 & 0.003 & Ramularia sp. & Ramularia sp. \\
\hline & OTU_251 & 0.007 & Ascomycota sp. & Ramularia sp. \\
\hline & OTU_3326 & 0.009 & Ramularia sp. & Ramularia sp. \\
\hline & OTU_2 & 0.012 & Ampelomyces sp. & Unknown \\
\hline \multirow{5}{*}{$\begin{array}{l}\text { Epiphyte + } \\
\text { Litter }\end{array}$} & OTU_66 & 0.003 & Bulleribasidium sp. & Bulleribasidium sp. \\
\hline & OTU_68 & 0.003 & Epicoccum sp. & Epicoccum sp. \\
\hline & OTU_82 & 0.003 & Capnodiales sp. & Dothideomycetes sp. \\
\hline & OTU_165 & 0.003 & Dioszegia athyri & Dioszegia sp. \\
\hline & OTU_226 & 0.003 & Agaricales sp. & Unknown \\
\hline \multirow{3}{*}{$\begin{array}{l}\text { Endophyte } \\
+ \text { Litter }\end{array}$} & OTU_87 & 0.033 & Ascomycota sp. & Paraconiothyrium sp. \\
\hline & OTU_1 & 0.033 & Glomerellaceae sp. & Colletotrichum sp. \\
\hline & OTU_127 & 0.035 & Diaporthales sp. & Diaporthe sp. \\
\hline \multirow{4}{*}{$\begin{array}{l}\text { Litter + } \\
\text { Soil }\end{array}$} & OTU_380 & 0.003 & Ascomycota sp. & Helotiales sp. \\
\hline & OTU_282 & 0.013 & Striatibotrys eucylindrospora & Striatibotrys sp. \\
\hline & OTU_193 & 0.02 & Cylindrocladium peruvianum & Cylindrocladiella $\mathrm{sp}$. \\
\hline & OTU_121 & 0.023 & Chalara sp. & Leotiomycetes sp. \\
\hline \multirow{5}{*}{$\begin{array}{l}\text { Epiphyte + } \\
\text { Endophyte } \\
\text { + Litter }\end{array}$} & OTU_4 & 0.003 & Ramularia sp. & Ramularia sp. \\
\hline & OTU_5 & 0.003 & Ramularia pratensis & Ramularia sp. \\
\hline & OTU_8 & 0.003 & Dothideomycetes sp. & Cladosporium sp. \\
\hline & OTU_10 & 0.003 & Didymellaceae sp. & Didymellaceae sp. \\
\hline & OTU_11 & 0.003 & Pleosporales sp. & Alternaria sp. \\
\hline
\end{tabular}




\section{Table 3 (on next page)}

Total, unique, and shared OTUs by substrate.

Comparison of the number of OTUs in each of four substrates. Shown are the total number of OTUs, the number of unique OTUs in each substrate and the number of OTUs shared between substrates. Total number of shared OTUs is the number of unique OTUs subtracted from the total number. OTUs were filtered to exclude those with a substrate-weighted abundance of less than $0.01 \%$. 
1 Table 3. Total, unique, and shared OTUs by substrate. Comparison of the number of OTUs

2 in each of four substrates. Shown are the total number of OTUs, the number of unique OTUs in

3 each substrate and the number of OTUs shared between substrates. Total number of shared

4 OTUs is the number of unique OTUs subtracted from the total number. OTUs were filtered to

5 exclude those with a substrate-weighted abundance of less than $0.01 \%$.

\begin{tabular}{|lcccc|}
\hline & Epiphyte & Endophyte & Litter & Soil \\
\hline Total OTUs & 268 & 202 & 421 & 364 \\
Unique OTUs & $5(2 \%)$ & $2(1 \%)$ & $64(15 \%)$ & $212(58 \%)$ \\
Shared with Epiphytes & - & $180(89 \%)$ & $247(59 \%)$ & $57(16 \%)$ \\
Shared with Endophytes & $180(67 \%)$ & - & $187(44 \%)$ & $43(12 \%)$ \\
Shared with Litter & $247(92 \%)$ & $187(93 \%)$ & - & $145(40 \%)$ \\
Total Shared & $263(98 \%)$ & $200(99 \%)$ & $357(85 \%)$ & $152(42 \%)$ \\
\hline
\end{tabular}

6 


\section{Figure 1}

Heatmap of OTU abundance by substrate.

A total of 42 OTUs were included in the heatmap, all which were significant indicator taxa as determined using the multipatt function in the indicspecies package. Taxa names were determined using the CONSTAX2 classifier. Sample names are included beneath each column, with host species as either Acer rubrum (Acer) and Carya ovata (Carya) and site number designated in the name.

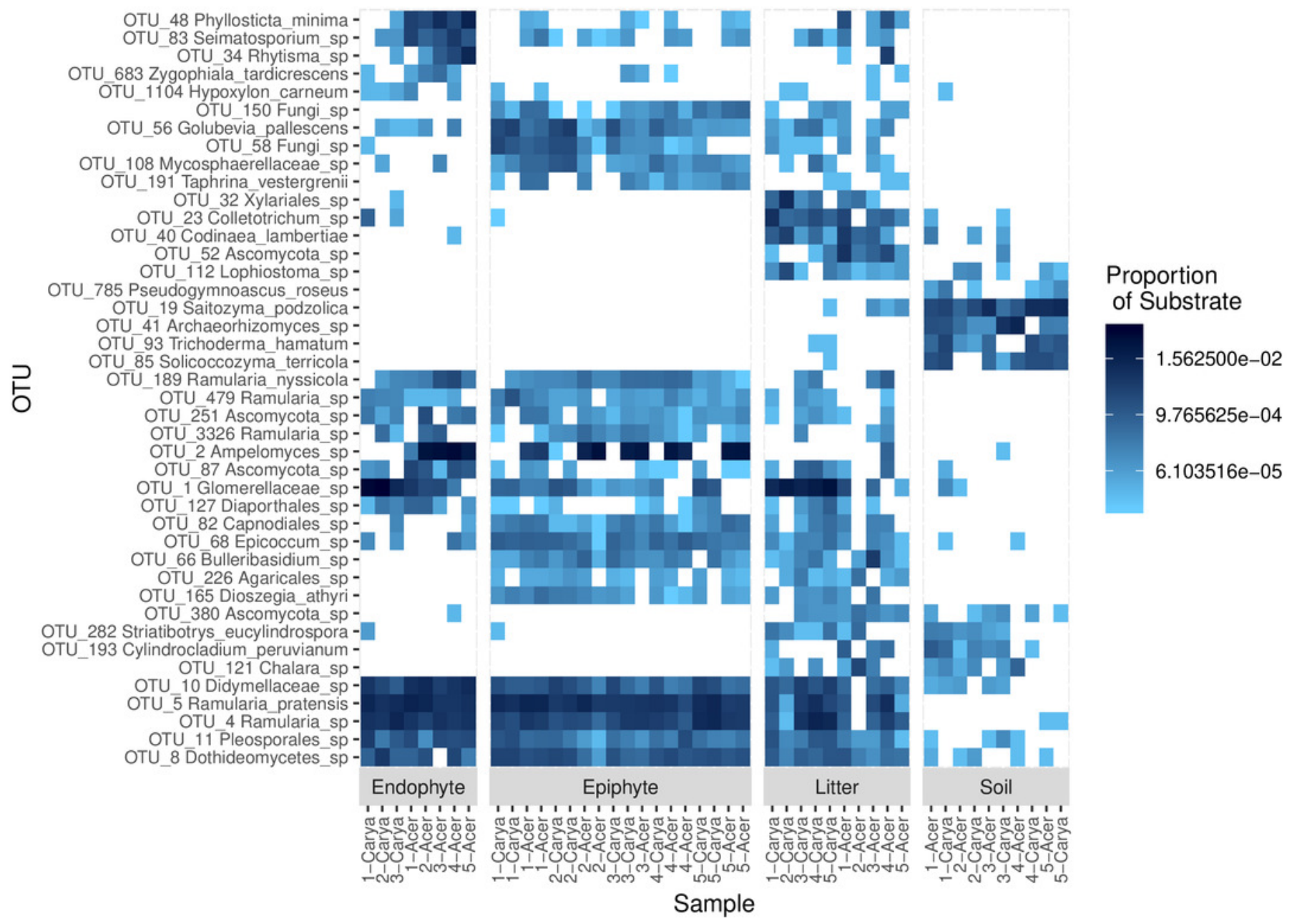


Figure 2

Venn diagram of shared OTUs by substrate.

657 OTUs were included which had substrate-weighted abundance greater than $0.01 \%$.

Overlapping regions indicate OTUs with at least one read in each of the substrates. 


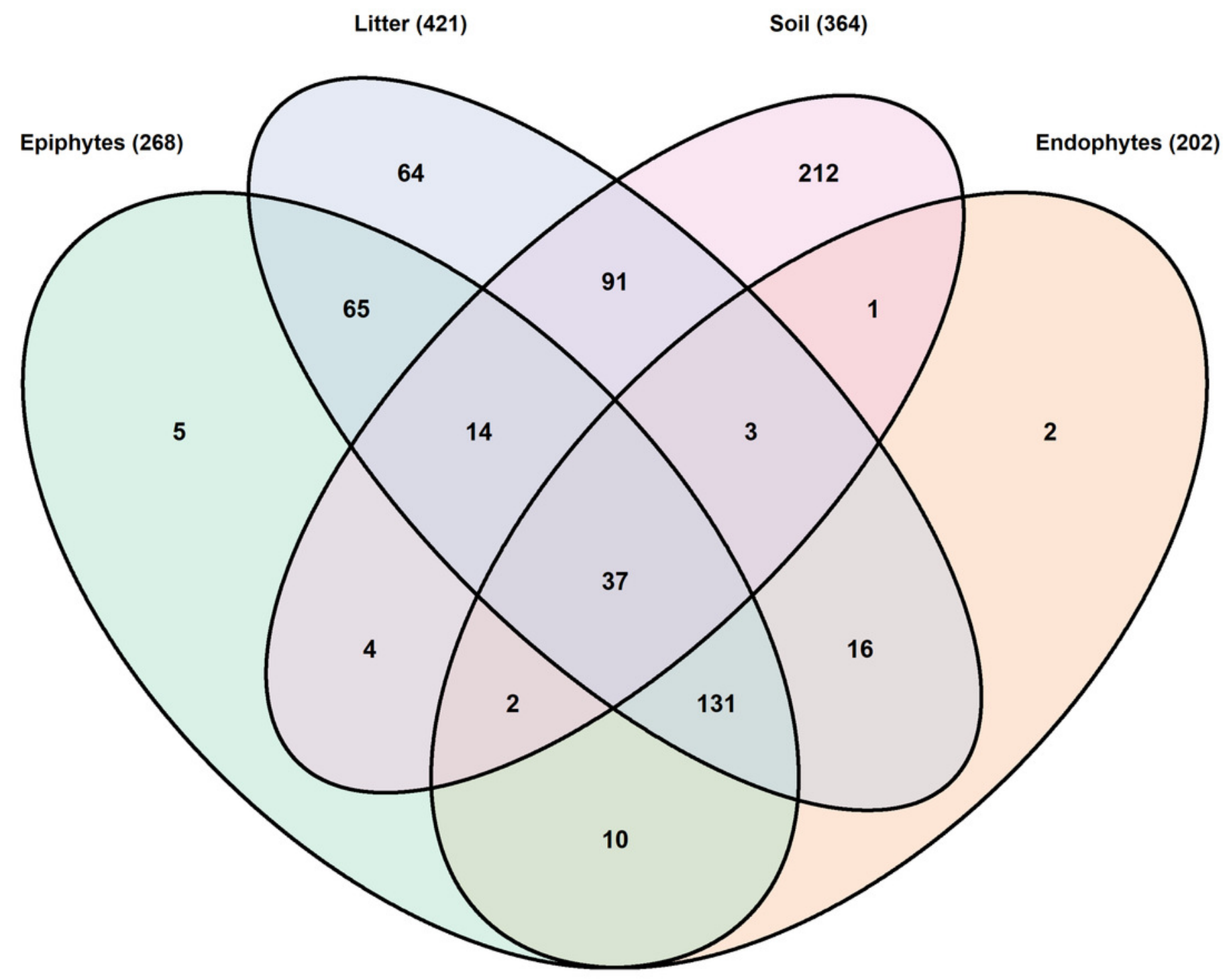




\section{Figure 3}

Comparison of community composition by substrate, host species, site, and swab material.
A) The most abundant 30 genera, determined by substrate-weighted abundance and CONSTAX2 classification, are displayed by the proportion of the community composed of OTUs classified within each genus. "Other" includes all OTUs not in the top 30, regardless of abundance. Samples are labeled by host species (genus name) and site with each substrate. B) Communities were ordinated using non-metric multidimensional scaling (NMDS) and Bray- Curtis distance, with ellipses representing $97 \%$ confidence interval estimates of centroids. C) Epiphyte communities were re-ordinated separately from the remaining samples. Ellipses show $97 \%$ confidence interval estimates of centroids of each swab material. 
A

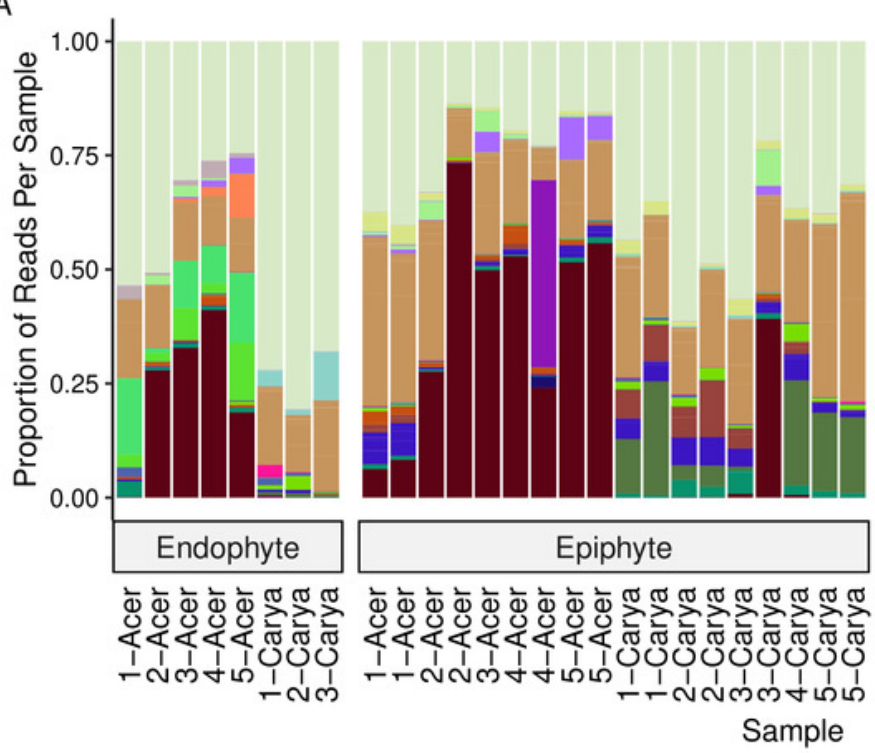

B

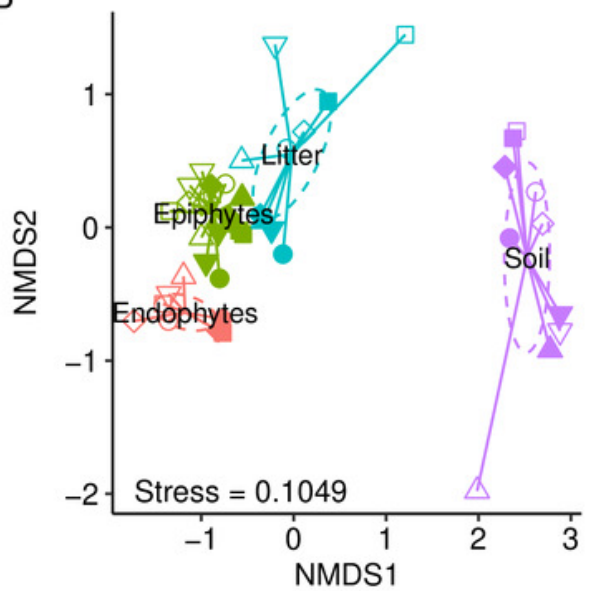

Host species

O Acer rubrum

- Carya ovata

Substrate

- Endophytes

- Epiphytes

- Litter

Site

○ 1

ㅁ 2

$\diamond 3$

$\triangle 4$

$\nabla 5$

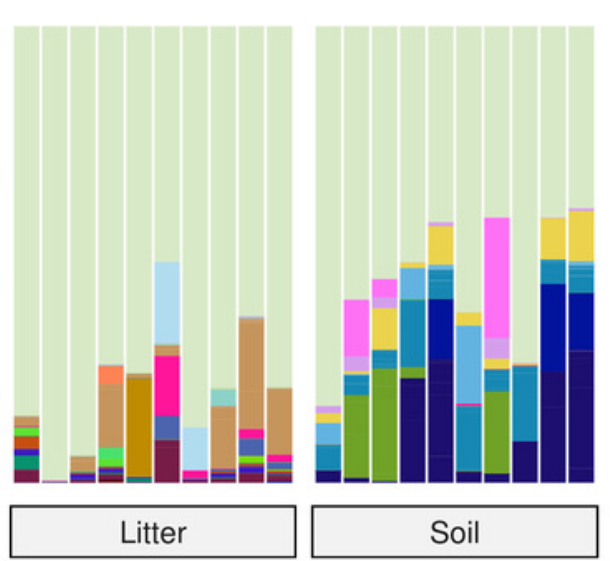

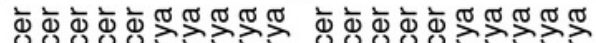

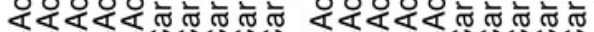

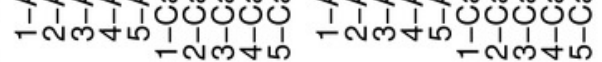

C

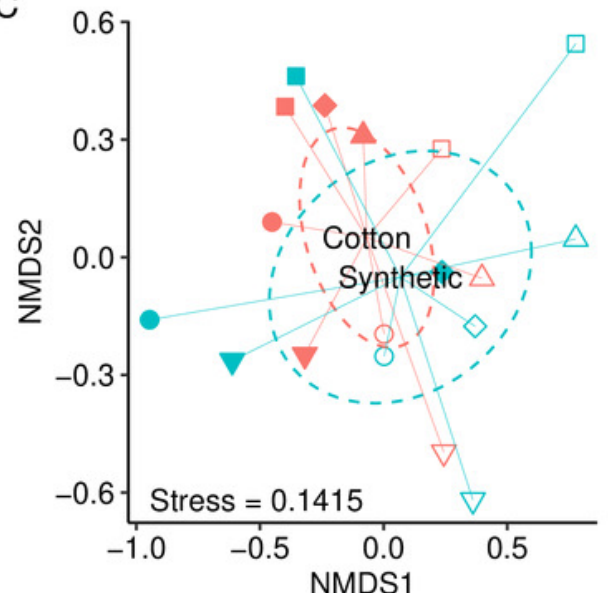

Genus

Other

Xenodactylaria

Tuber

Tomentella

Taphrina

Sphaerulina

Seimatosporium

Scleroramularia

Sawadaea

Saitozyma

Russula

Rhytisma

Ramularia

Plectosphaerella

Plagiostoma

Phyllosticta

Periconia

Paraphaeosphaeria

Mycosphaerella

Mortierella

Lareunionomyces

Golubevia

Exobasidium

Erysiphe

Dothiora

Colletotrichum

Clavulinopsis

Archaeorhizomyces

Ampelomyces

Host Species

- Acer rubrum

- Carya ovata

Swab Material

- Cotton

- Synthetic

Site

○ 1

ㄴ 2

$\diamond 3$

$\begin{array}{ll}\triangle & 4 \\ \nabla & 5\end{array}$ 


\section{Figure 4}

Richness and within-sample diversity of fungal communities by swab material.

Epiphyte communities sampled with swabs were compared by observed richness, Shannon, and Inverse Simpson estimates of within-sample (alpha) diversity. Diversity estimates were determined using the phyloseq package. Test stastistic $F$ and $p$-values are derived from linear mixed models with swab material as a fixed effect and leaf sampled as a random intercept effect.
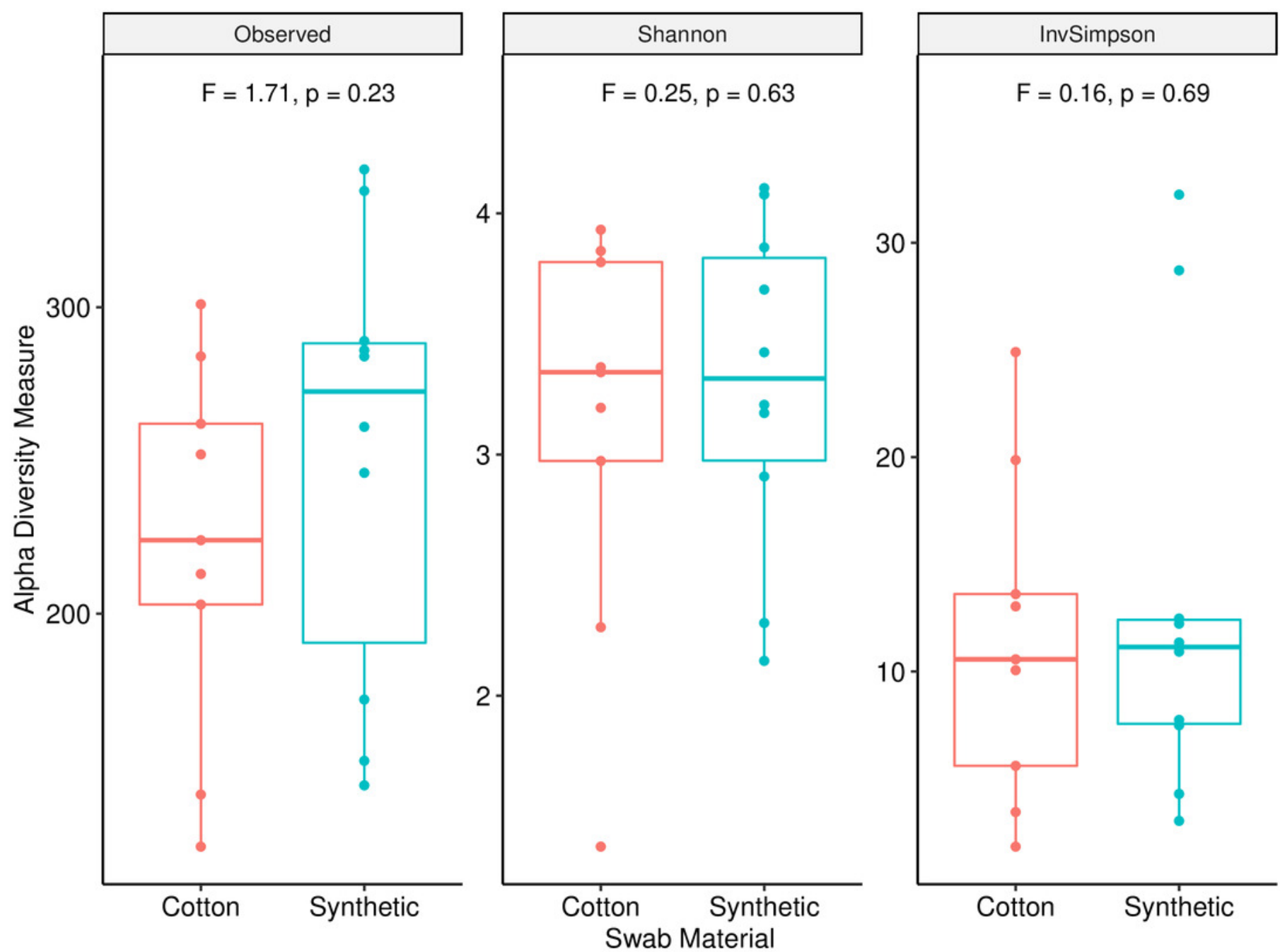